\title{
Agôn
}

Revue des arts de la scène

Critiques | Saison 2016-2017

\section{Die Kabale des Scheinheiligen - Das Leben des Herrn de Molière, d'après Mikhaïl Boulgakov, mise en scène de Frank Castorf}

20 juillet : 11 jours après, retour sur une œuvre somme où la fin d'un monde s'énonce avec une vitalité saisissante

\section{Caroline Châtelet}

\section{(2) OpenEdition}

Journals

Édition électronique

URL : http://journals.openedition.org/agon/4022

DOI : $10.4000 /$ agon.4022

ISSN : 1961-8581

Éditeur

Association Agôn

Référence électronique

Caroline Châtelet, "Die Kabale des Scheinheiligen - Das Leben des Herrn de Molière, d'après Mikhaïl Boulgakov, mise en scène de Frank Castorf », Agôn [En ligne], Critiques, mis en ligne le 20 juillet 2017 , consulté le 23 septembre 2020. URL : http://journals.openedition.org/agon/4022 ; DOI : https:// doi.org/10.4000/agon.4022

Ce document a été généré automatiquement le 23 septembre 2020.

Association Agôn et les auteurs des articles 


\section{Die Kabale des Scheinheiligen - Das Leben des Herrn de Molière, d'après Mikhail Boulgakov, mise en scène de Frank Castorf}

20 juillet : 11 jours après, retour sur une œuvre somme où la fin d'un monde s'énonce avec une vitalité saisissante

Caroline Châtelet

\section{RÉFÉRENCE}

Die Kabale der Scheinheiligen, Le Roman de Monsieur de Molière, d'après Mikhaïl Boulgakov, Parc des expositions, Festival d'Avignon, du 8 au 13 juillet

1 Il y a deux ans, dans le cadre du Festival d'Avignon, Krystian Lupa présentait Wycinka Holzfällen (Des arbres à abattre) ${ }^{1}$. Un spectacle particulier : si le metteur en scène polonais adaptait l'œuvre de l'auteur autrichien Thomas Bernhard, il y injectait plus que jamais ses propres questionnements et problématiques. Krystian Lupa ayant quitté en 2013 la direction du Stary Teatr de Cracovie pour un autre à Varsovie, la question des liens entre l'artiste et la puissance politique, l'hypocrisie de ces rapports, la compromission pour pouvoir exercer son art, parfois au risque de l'appauvrir, traversaient toute la mise en scène. À sa manière, à son tour, Die Kabale des Scheinheiligen - Das Leben des Herrn de Molière (d'après La Cabale des dévots et La Vie de monsieur de Molière de Mikhaïl Boulgakov) monté par Frank Castorf se révèle essentielle. Un spectacle somme, dans lequel Castorf aborde ces mêmes enjeux en concevant une œuvre puissante, toute entière dédiée à l'art du théâtre et à ses interprètes.

2 Fin 2016, Frank Castorf a quitté la direction de la Volksbühne, théâtre qu'il a dirigé pendant vingt-trois ans, à Berlin. Avec son départ c'est, certes, une page qui se tourne pour ce théâtre mythique par son projet artistique, son public populaire et son 
engagement. Mais c'est, également, un pas de plus vers de nouveaux modes de conception de la culture. Puisque ce n'est pas une personnalité issue du théâtre qui a été nommé pour succéder à Frank Castorf, mais Chris Dercon, historien de l'art, commissaire d'exposition et directeur du musée de la Tate Modern à Londres jusqu'à fin 2016. Cette nouvelle avait fait grand bruit lors de son annonce - suscitant des réactions dans le domaine culturel allemand - et la critique portait sur son profil, mais surtout sur sa culture. Se définissant lui-même comme néolibéral (tout un programme), Chris Dercon porte une vision de l'art inscrite dans un marché, et soumise à ce dernier (donc, à son système).

3 Dans l'œuvre à tiroirs qu'est Die Kabale ..., certains éléments de la scénographie évoquent cette présence du marché. Parmi les différents modules scénographiques (roulotte-théâtre de tréteaux des comédiens ; chambres royales évoquant les tentes des camps de la légion romaine) l'une des deux chambres royales a ses lourdes tentures siglées Louis Vuitton, tandis que son chapiteau arbore un médaillon à l'effigie de Versace. Énonciation de la collusion existant entre grands groupes du luxe et pouvoir politique; désignation du mécénat tel qu'il est pratiqué dans de grandes institutions muséales, la Tate Modern en tête (à titre d'exemple, l'exposition de Yayoi Kusama en 2012 à la Tate était soutenue par Louis Vuitton, et avait été suivie d'un lancement d'une collection Vuitton réalisée en collaboration avec l'artiste japonaise). Face à ces représentations du pouvoir, il flotte au sommet de la roulotte des comédiens un drapeau avec une roulotte stylisée, dont les roues évoquent le logo de la Volksbühne. Auparavant installée devant le théâtre à Berlin, la sculpture de ce logo créé en 1992 par Bert Neumann était placée, pour ces dernières représentations de la troupe, devant le Parc des expositions, à Avignon.

Tandis que La Vie de monsieur de Molière de Boulgakov est une biographie romancée de la vie de Jean-Baptiste Poquelin, La Cabale des dévots (devenue ici la «cabale des hypocrites ", les adversaires n'étant plus forcément religieux) est une pièce dans laquelle Boulgakov imagine comment une organisation s'employa à discréditer le dramaturge et à faire interdire Tartuffe. Ouvrant et clôturant le spectacle, ces deux œuvres, présentes de façon fragmentaire, sont entremêlées d'extraits de pièces de Molière - donnant lieu à des moments de jeu d'anthologie -, de références à Rainer Werner Fassbinder, ou encore à Boulgakov et à ses relations avec le pouvoir soviétique. Avec un art du montage maîtrisé, le metteur en scène allemand enchâsse dans une fluidité géniale les périodes historiques, les niveaux de discours, les plans, la vidéo, les langues et le théâtre. La vidéo, d'ailleurs, que Castorf aime utiliser à l'envi, se révèle un puissant levier dramaturgique. Suivant au plus près les comédiens dans leur déplacement, nous rendant les scènes passionnelles entre Molière et sa maîtresse Madeleine Béjart, ces images racontent également un rapport au pouvoir politique et aux médisa. Les intrigues et les négociations nous étant toujours inaccessibles, elles se jouent ici dans les chambres royales, ou au loin, en fond de scène. Seule la vidéo nous en rend compte, le filtre déformant du gros plan insistant sur les affects plutôt que de travailler à une réflexion critique. Face à cette culture du sensationnel - tel qu'il est véhiculé par les grands médias - le théâtre serait voué à disparaître. Un constat qui contamine l'ensemble de l'œuvre. Tandis que le jeu des comédiens se teinte de mélancolie et de gravité - tel Jean-Damien Barbin qui quitte un moment son personnage pour signaler qu'avec ces représentations avignonnaises cessent les tournées des productions de la Volksbühne - les courses effrénées, frénétiques, de la première partie cèdent le pas à des déplacements plus lents dans la seconde. Dans cette 
guerre de positions entre le théâtre et le marché, le théâtre est perdant : la fin de ce monde approche et lorsque Die Kabale se termine, il ne demeure au plateau qu'une chambre royale, la roulotte ayant disparu du centre de la scène.

\section{NOTES}

1. http://journals.openedition.org/agon /3258 